Int. J. Morphol.,

31(3):980-985, 2013.

\title{
Effect of Amnion-Wrapped Allogenic Nerve Bridging on Peripheral Nerve Injury
}

\author{
Efecto del Puente Alogénico de Nervio Envuelto en Membrana \\ Amniótica sobre la Lesión de Nervio Periférico
}

Yan-Ru Zhang,*;*; Ge-Chen Zhang***; Qiu-Hao Liu**** \& Yi-Sheng Wang ${ }^{* * *}$

ZHANG, Y.; ZHANG, G.; LIU, Q. \& WANG, Y. Effect of amnion-wrapped allogenic nerve bridging on peripheral nerve injury. Int. J. Morphol., 31(3):980-985, 2013.

SUMMARY: This work aims to investigate the effect of fetal amnion-wrapped acellular allogenic nerve transplantation on peripheral nerve injury (PNI) in dogs and to explore its advantages and feasibility in PNI repair. A total of 15 dogs were divided into three groups: the allogenic nerve transplantation (A), amnion-wrapped allogenic nerve transplantation (B), and allogenic nerve donor (C) groups. Neurite counts after myelin and H-E stainings, soleus muscle action potentials, and sciatic nerve conductive velocities were compared between the A and B groups at $16 \mathrm{w}$ after operation. The B group showed better nerve regeneration than the A group at $16 \mathrm{w}$. Compared with the A group, the B group showed a better growth continuity of the transplanted nerve and milder inflammatory reactions around the nerve. The B group presented much more proliferated Schwannocytes and regenerated nerve fibers than the A group. The neurite density and the amplitude of the soleus muscle action potentials in the B group were significantly higher than those in the A group $(\mathrm{P}<0.05)$. The two groups did not show significant differences in nerve conductive velocities $(\mathrm{P}>0.05)$. Amnion-wrapped acellular allogenic nerve transplantation can improve defected nerve morphology and the quality of transplanted nerve regeneration.

KEYWORDS: Amnion; Allogenic transplantation; Nerve regeneration

\section{INTRODUCTION}

Peripheral nerve injury (PNI) is a common medical condition. The defected nerve, if not repaired as early as possible, can cause long-term denervation and neurotrophy failure for the target organ. This leads to a series of denervation manifestations, such as muscle atrophy, loss of sensory function, etc. and ultimately, these manifestations seriously affect the patient's sensorimotor function (Sondell et al., 1998; Chen \& Zhu, 1990). Although autologous nerve transplantation can achieve a reliable effect on PNI, its application is greatly restricted by limited sources. Meanwhile, the cutting-out of autologous nerve always causes a new trauma for the patient, leading to the occurrence of cicatrix, numbness, neuroma at the donor site after operation. Due to these reasons, autologous nerve transplantation cannot satisfy the clinical requirements for the treatment of PNI. Acellular allogenic nerve can provide effective scaffold substances, such as nerve matrix microtubules and Schwann cell basal lamina for defected nerve regeneration. For this reason, it has become a research hotspot nowadays. Amniotic membrane is a layer of biomembrane between mother and the fetus. It has a good biological compatibility and is rich in sources; its immune privilege can function as the microenvironment for nerve regeneration after acellular allogenic transplantation; further, its wrapping of the defected nerve can form a sham sheath, which plays a basilar membranous role to clear the obstacles to the directional regeneration of the nerve fibers (Dai et al., 2001; Tang et al., 2002; Zhong et al., 2002; Toba et al., 2006).

In the current study, acellular allogenic nerve wrapped by amniotic membrane was applied for sciatic nerve injury repair in dogs. The feasibility of amnion-wrapped acellular allogenic nerve transplantation was further explored.

\footnotetext{
* Department of Orthopaedics, The First Affiliated Hospital, ZhengZhou University, Zhengzhou, China;

** Basic Medical School of ZhengZhou University, Zhengzhou, China.

**** Department of Orthopaedics, Hospital of Baimashi Luoyang, China.

***** Department of Orthopaedics, 153 Hospital of China People's Liberation Army, China.
} 


\section{MATERIAL AND METHOD}

This study was carried out in strict accordance with the recommendations in the Guide for the Care and Use of Laboratory Animals of the National Institutes of Health. The animal use protocol has been reviewed and approved by the Institutional Animal Care and Use Committee (IACUC) of Zhengzhou University. A total of 15 healthy hybrid dogs of either sex, weighing $20 \pm 4 \mathrm{~kg}$, were selected. They were divided into three groups: the allogenic nerve transplantation ( $\mathrm{A} ; \mathrm{n}=6)$, amnion-wrapped allogenic nerve transplantation $(\mathrm{B} ; \mathrm{n}=6)$, and allogenic nerve donor $(\mathrm{C} ; \mathrm{n}$ $=3$ ) groups. All the dogs were in a good condition with luster fur and normal eating and activities. They were bred in separate cages and allowed free eating and drinking.

Human amnion was taken from a normally delivered healthy fetus. Preparation procedures were conducted by reference to the method reported (Gulati, 1995). The tissue was repeatedly washed until it was observed clear and transparent under the light microscope. The membrane was then put into $0.1 \% \mathrm{NH} 4 \mathrm{OH}$ solution. Afterwards, it was taken out and put into phosphate buffer at $250 \mathrm{ml}$ (containing 400,000 units of penicillin and 40,000 units of gentamycin). The membrane was cut into $2-4 \mathrm{~cm}$ $\mathrm{x} 4-9 \mathrm{~cm}$ pieces and then kept at $-40{ }^{\circ} \mathrm{C}$.

The dogs in the $\mathrm{C}$ group were anesthetized with $100 \mathrm{mg}$ of Sumianxin. A $10 \mathrm{~cm}$ longitudinal incision was made in the medial region of the right thigh. The femoral artery was exposed through the muscular space and then cut off to kill the animal. The biceps muscle was pulled backward to expose the sciatic nerve. Bilateral sciatic nerves of approximately $7-11 \mathrm{~cm}$ in length were cut off and then extracted using Sondell's method (Toba et al.). The extracted acellular nerves had good appearance. They underwent germicidal treatment.

Dogs were intravenously injected with $2.5 \%$ pentobarbital sodium for 2-2.5 hours' anesthesia according to $10 \mathrm{mg} / \mathrm{kg}$. Operative procedures were conducted. The anesthetized dogs were placed in a prone position with the mouth and teeth immobilized by tape. The four limbs were separated and fixed on a cork board by bandages. After hair removal with $8 \%$ sodium sulfide, the right hind limb and the skin $15 \mathrm{~cm}$ around the incision site were disinfected with iodophors and small towels were then prepared. Dogs in the A and B groups were subjected to a longitudinal incision in the right hind limb. The biceps muscle was pulled backward to expose the sciatic nerve. Sciatic nerve segments at $5.5,6.0$, and $7.8 \mathrm{~cm}$ in lengths were respectively cut off. In the A group, an allogenic nerve segment with the corresponding length was selected for epineurial suture using non-invasive thread $8 / 0$ under the microscope (x 10). The B group received amnion-wrapped acellular allogenic nerve bridging. Specifically, the length of the nerve loss was measured, and an allogenic nerve with the corresponding length was selected; $2 \mathrm{~mm}$ was removed from the distal end of the allogenic nerve for endend involution using non-invasive thread $8 / 0$ under the microscope; amniotic wrapping was then performed (the anastomotic stomas did not receive suturing for anastomoses); the membrane was stuck together and fixed with ear-brain glue to form a sealed compartment (the membrane should be $1.5 \mathrm{~cm}$ beyond both the distal and proximal broken ends in case that the glue contaminates the anastomotic stomas). The sciatic nerve was re-covered by the muscles. After hemostasis, the incision was sutured with silk thread 1 . The wound surface was covered with two layers of gauze and then fixed with bandages.

The dogs were bred separately. Mental status, limb movements, wound, and motor function of the affected limb were carefully observed and recorded within $8 \mathrm{w}$ after operation. Foot ulcer formation and healing, the functional recovery of the affected limbs, and complications were carefully observed and recorded within $16 \mathrm{w}$ after operation.

Abdominal anesthesia was performed with $2 \%$ pentobarbital sodium according to $40 \mathrm{mg} / \mathrm{kg}$ at $16 \mathrm{w}$. The transplanted sciatic nerve as well as the sciatic nerve on the opposite side were exposed and isolated. Stimulating electrodes were placed at the proximal anastomotic stoma. Indexes of the soleus muscle action potentials on the affected side, bilateral motor nerve conduction velocities (MNCV), and bilateral sensory nerve conduction velocities (SNCV) were detected.

The nerve segment $1 \mathrm{~cm}$ above the distal anastomotic stoma and $1 \mathrm{~cm}$ below the proximal stoma were drawn in both groups at $16 \mathrm{w}$. The sample was routinely fixed with $10 \%$ formalin, embedded with paraffin and then serially sectioned. The sections included the range $2 \mathrm{~mm}$ beyond and below the anastomotic stoma. Longitudinal sections were made for the anastomotic stoma while transverse sections were made for the rest. Hematoxylin and esosin (HE) staining and myelin staining were then performed. Neurites in the nerve tract were counted and the area of the nerve tract was measured for neurite density calculation.

Data were presented as Mean \pm DS and analyzed using the SPSS13.0 software. T-test was performed for comparison between groups. $\mathrm{P}<0.05$ was considered significant. 


\section{RESULTS}

General conditions. Dogs in both groups began to show foot red swelling and ulcerating on the affected side from 2 $\mathrm{w}$ to $7 \mathrm{w}$ after operation. They limped due to weakened triceps surae muscle strength, and their affected ankle joints couldn't stand straight while walking. After $7 \mathrm{w}$, their motor functions recovered in different degrees, but the foot ulcers in the B group healed obviously faster than those in the A group. At $16 \mathrm{w}$, the motor function recovery in the B group was significantly better. In this group, the nerve function and triceps surae muscle strength began to recover, and the dogs were able to stand up on their right hind limbs. In contrast, the A group did not have a good nerve regeneration effect with long-term unhealed foot red swelling and ulcers.

Transplanted nerves. Both groups underwent abdominal anesthesia with $2 \%$ pentobarbital sodium at $16 \mathrm{w}$ to expose the sciatic nerve on the transplanted side. In the A group, the transplanted nerve had a good continuity but in serious adhesion to the surrounding tissues; local scars caused by the hyperblastosis of the surrounding tissues could be observed; indurations at the anastomotic stomas could be felt with local pear-shaped changes; the vascularization on the nerve surface was poor, and the transplanted nerve at both the proximal and distal ends attenuated and hardened. In the B group, the transplanted nerve had a good continuity without shedding or sclerotic cicatricial adhesion to the surrounding tissues; no noticeable inflammatory reaction around the transplanted nerve was observed; an obvious capillary network appeared on the nerve surface; the anastomotic stomas dilated slightly but without indurations or pear-shaped changes; and the proximal and distal ends of the transplanted nerve appeared basically normal.

Histological observation. HE staining showed medullated nerve fibers but with an irregular and uneven density distribution in both groups (Fig. 1).

Neurites. Neurite density refers to the number of neurites per unit area of the nerve tract, which reflects nerve fiber regeneration. Statistical analysis showed that the neurite density of the B group was significantly higher than that of the A group $(\mathrm{P}<0.05$; Table I). This result suggests that amnion-wrapped allogenic nerve bridging can better aid neurite regeneration, nerve fiber threading, and nerve function recovery after PNI.

Electromyography. Electromyography showed that the amplitude of the soleus muscle evoked potentials in the B group was significantly higher than that in the A group at 16

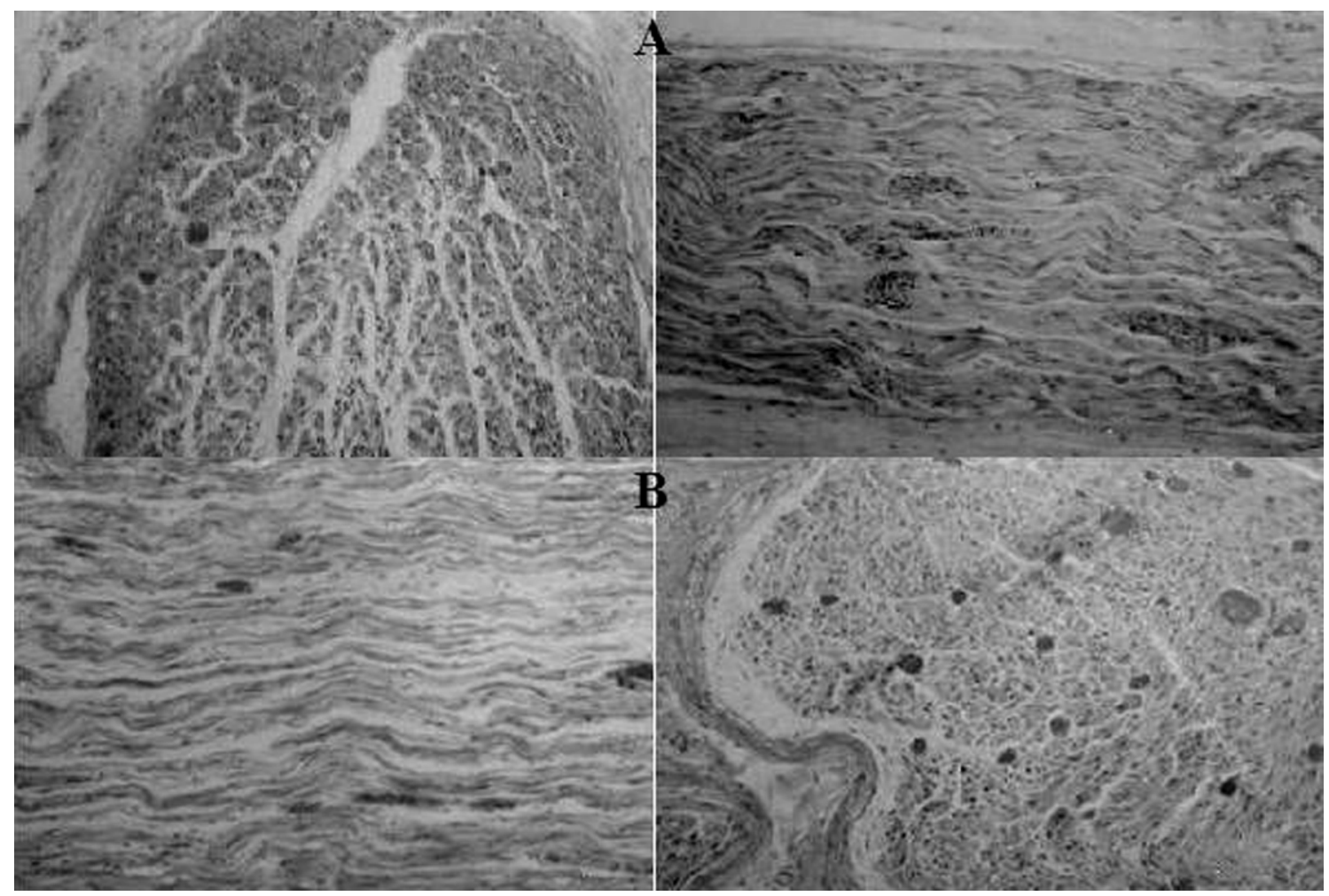

Fig. 1. HE staining of the transplanted nerve at $16 \mathrm{w}$ after operation (x 400). A) group A; B) group B. 
w; afterwards, the latency period between motor evoked potentials gradually reduced with an increasing amplitude in both groups $(\mathrm{P}<0.05$; Table II).

Electrophysiology. The A and B groups did not show a significant difference in sciatic nerve conduction velocity at $16 \mathrm{w}(\mathrm{P}>0.05)$, but both group showed a significant difference as compared to the normal sciatic nerve $(\mathrm{P}<0.05)$ (Table III).

Table I. Axon density at 16 weeks after operation $\left(/ 100 \mathrm{~mm}^{2}\right)( \pm \mathrm{s})$

\begin{tabular}{cl}
\hline Group & Axon density \\
\hline A & $0.725 \pm 0.032$ \\
B & $0.913 \pm 0.026^{*}$ \\
\hline
\end{tabular}

Note: Compared with group A *P $<0.05$

Table II. Electromyography comparison of soleus $( \pm \mathrm{s})$.

\begin{tabular}{lll}
\hline Group & Wave $(\mathrm{mv})$ & Time $(\mathrm{ms})$ \\
\hline A & $2.58 \pm 0.71$ & $4.09 \pm 1.32$ \\
B & $5.46 \pm 1.13^{*}$ & $12.26 \pm 2.57^{*}$ \\
Control & $12.91 \pm 2.58$ & $20.24 \pm 3.49$ \\
\hline
\end{tabular}

Note: Compared with group A *P $<0.05$

Table III. Nerve conduction velocity compression at 16 weeks after operation $(\mathrm{m} / \mathrm{s})( \pm \mathrm{s})$

\begin{tabular}{lll}
\hline Group & MNCV & SNCV \\
\hline A & $34.25 \pm 4.69$ & $25.15 \pm 4.48$ \\
B & $35.71 \pm 3.93^{*}$ & $26.38 \pm 4.27^{*}$ \\
Normal control & $39.48 \pm 4.54$ & $28.62 \pm 5.16$ \\
\hline
\end{tabular}

Note: Compared with group $\mathrm{A} * \mathrm{P}<0.05$.

\section{DISCUSSION}

Recent years has witnessed that the application of the optimized chemical extraction method in handling allogenic nerves as bridge grafts can achieve a good curative effect. Thus, this method was adopted in the present study. It effectively cleared the immunogenicity of the xenogenous nerve, and meanwhile preserved Schwann cell basilar membrane and the integrity of its organizational structure. The results in this study showed that the transplanted nerve in the B group had a good continuity without cicatricial adhesion to the surrounding tissues nor shedding or isolation and no obvious inflammatory reaction occurred to the surrounding tissues at $16 \mathrm{w}$ after operation (the result is consistent to those reported (Lassner et al., 1989; Sondell et al.; Mohammad et al., 2000; Dubovy et al., 2001; Kubo et al., 2001; Mligiliche et al., 2002; Hudson et al., 2004a, 2004b; Matsumoto et al., 2005; Sun et al., 2006; Xu et al., 2007), whereas the transplanted nerve in the A group seriously adhered to the surrounding tissues, the proximal and distal ends of the nerve attenuated and hardened and poor vascularization appeared on the transplanted nerve surface at the same detection time point. These results further demonstrate that the modified chemical extraction method can reduce the incidence of post-operative immunologic rejection.

Amnion is the membrane between the maternal body and fetus, which has an immune privilege and a good biological compatibility. The nerve regeneration chamber formed by amnion has low immunogenicity, and meanwhile can effectively guide nerve regeneration, providing an excellent microenvironment for defected nerve repair (Sondell et al.; Dubovy et al.; Hudson et al., 2004b). In the present study, amnion-wrapped allogenic nerve bridging for defected sciatic nerve repair in dogs achieved a satisfactory effect. The results showed that the amnion-wrapped allogenic transplanted nerve had a good continuity without cicatricial adhesion to the surrounding tissues nor shedding or isolation and a neocapillary network appeared on the transplanted nerve surface at $16 \mathrm{w}$ after operation; by contrast, the nonwrapped allogenic transplanted nerve seriously adhered to the surrounding tissues, its proximal and distal ends attenuated and hardened and poor vascularization appeared on its surface. These results suggest that amnion-wrapped allogenic nerve bridging does not cause rejection reaction and can better aid the regeneration of neurites and nerve fiber cells as well as nerve function recovery in defected sciatic nerve repair. MNCV and SNCV are two commonlyobserved indexes of peripheral nerve electrophysiologic function, which reflect the functions of the motor and sensory nerve fibers in sciatic nerve. The present study showed that the amplitude of the soleus muscle evoked potentials in the B group was significantly higher than that in the A group at $16 \mathrm{w}$ after operation, and both groups presented a gradually shortened latency period between evoked potentials and a gradually-increased potential amplitude afterwards. But, the two groups did not show a significant difference in nerve conduction velocities at $16 \mathrm{w}(\mathrm{P}>0.05)$. This was presumably subject to too short observation time.

In this study, the anastomotic stomas of the amnionwrapped acellular allogenic nerve presented only slight adhesion to the surrounding tissues, no obvious inflammatory reactions, less local cicatricial tissues, milder resistance to nerve regeneration, and higher neurite density, and the soleus muscle evoked potentials showed a higher amplitude. These results show that allogenic nerve after chemical extraction 
can serve as a nerve graft substitute with low antigenicity. This overcomes the obstacle posed by immunologic rejections to grafts in clinical practice. In addition, this study made full use of the characteristics of fetal amniotic membrane, such as semi-transparency, low immunogenicity, and inhibitory effects on inflammatory reactions and cicatricial hyperplasia to wrap the allogenic nerve to form a relatively sealed and longilineal pipe - a nerve compartment. By doing this, the anastomotic stomas were effectively protected from the interference from the sutures. In the meantime, the combined application of medical glue and the selection of a diameter-, length-, and property-matching allogenic acellular sciatic nerve took full advantage of contact induction, which, on the one hand, guided the regenerated neurites to grow from the proximal end of the broken nerve to the distal end with high selectivity to reduce their mis-oriental growth, and guaranteed the anastomosis intensity to avoid the shedding and dissociation of the graft at the broken ends on the other, playing a promotive effect on peripheral nerve repair. This study demonstrates that bringing different action mechanisms during nerve regeneration into full play to provide a good microenvironment for nerve regeneration can realize the highly selective regeneration of nerve fibers, reduce the misoriental growth of neurites and promote nerve function recovery. This study also demonstrates that amnion-wrapped allogenic nerve bridging is an easy and effective PNI repair method with a promising application outlook, which can reduce scar formation at stoma sites, improve regeneration microenvironment and benefit nerve regeneration.

For a long length of nerve loss, this method does not impose a new trauma and pains on the sufferer, nor sacrifices the sensory motor controls of other nerves, offering possibilities of nerve function recovery and affected limb rehabilitation. However, whether amnion-wrapped allogenic nerve transplantation is applicable for clinic use still needs more advanced mammal-involved experimental studies to testify.

Conflict of interest statement, The authors declare that they have no conflict of interest.

ZHANG, Y.; ZHANG, G.; LIU, Q. \& WANG, Y. Efecto del puente alogénico de nervio envuelto en membrana amniótica sobre la lesión de nervio periférico. Int. J. Morphol., 31(3):980-985, 2013.

RESUMEN: El objetivo fue investigar el efecto del trasplante alogénico de nervio acelular envuelto en membrana amniótica fetal sobre la lesión del nervio periférico (LNP) en perros, y explorar sus ventajas y viabilidad en la reparación de LNP. Quince 15 perros se dividieron en tres grupos: grupo trasplante alogénico de nervio (A), grupo trasplante alogénico de nervio envuelto en membrana amniótica (B), y grupo donante alogénico de nervio (C). Se compararon el recuento de neuritas posterior a la tinción de hematoxilinaeosina (HE) y para mielina, potenciales de acción del músculo sóleo, y velocidades conductoras nerviosas del nervio ciático entre los grupos A y B, 16 semanas después de la operación. El grupo B mostró una mejor regeneración de los nervios que el grupo A a las 16 semanas. En comparación con el grupo A, el grupo B mostró una mejor continuidad del crecimiento del nervio trasplantado con reacciones inflamatorias leves alrededor del nervio. El grupo B presentó fibras nerviosas donde proliferaron más los Schwannocitos y regeneración que el grupo A. La densidad de las neuritas y la amplitud de los potenciales de acción del músculo sóleo en el grupo B fueron significativamente más altos $(\mathrm{p}<0,05)$. Ambos grupos no mostraron diferencias significativas en las velocidades conductoras nerviosas (P> 0,05). El trasplante alogénico de nervio acelular envuelto en membrana amniótica puede mejorar la morfología del nervio lesionado y la calidad de regeneración del nervio trasplantado.

PALABRAS CLAVE: Membrana amniótica; Trasplante alogénico; Regeneración nerviosa.

\section{REFERENCES}

Chen, Y. G. \& Zhu, J. K. Experimental research of human amniotic membrane basement membrane bridging nerve defects. Chin. J. Microsurg., 3:20-3, 1990.

Dai, C. C.; Wang, W. \& Cao, Y. An experimental study of repairing nerve gap with acellular basal lamina tubes. Zhonghua Zheng Xing Wai Ke Za Zhi, 17(6):366-8, 2001.

Dubovy, P.; Svizenska, I.; Klusakova, I.; Zítková, A.; Houst'Ava, L. \& Haninec, P. Laminin molecules in freeze-treated nerve segments are associated with migrating Schwann cells that display the correspondinga6b1 integrin receptor. Glia, 33(1):36-44, 2001.

Gulati, A. K. Immunological fate of Schwann cell-populated acellular basal lamina nerve allografts. Transplantation, 59(11):1618-22, 1995.

Hudson, T. W.; Liu, S. Y. \& Schmidt, C. E. Engineering an improved acellular nerve graft via optimized chemical processing. Tissue Eng., 10(9-10):1346-58, 2004a. 
Hudson, T. W.; Zawko, S.; Deister, C.; Lundy, S.; Hu, C. Y.; Lee, $\mathrm{K}$.; et al. Optimized acellular nerve graft is immunologically tolerated and supports regeneration. Tissue Eng., 10(1112):1641-51, 2004b.

Kubo, M.; Sonoda, Y.; Muramatsu, R. \& Usui, M. Immunogenicity of human amniotic membrane in experimental xenotransplantation. Invest. Ophthalmol. Vis. Sci., 42(7):153946,2001

Lassner, F.; Schaller, E.; Steinhoff, G.; Wonigeit, K.; Walter, G. F. $\&$ Berger, A. Cellular mechanisms of rejection and regeneration in peripheral nerve allografts. Transplantation, 48(3):386-92, 1989.

Matsumoto, K.; Ohnishi, K.; Kiyotani, T.; Sekine, T.; Ueda, H.; Nakamura, T.; et al. Peripheral nerve regeneration across an 80-mm gap bridged by a polyglycolic acid (PGA)-collagen tube filled with laminin-coated collagen fibers: a histological and electrophysiological evaluation of regenerated nerves. Brain Res., 868(2):315-28, 2005.

Mligiliche, N.; Endo, K.; Okamoto, K.; Fujimoto, E. \& Ide, C. Extracellular matrix of human amnion manufactured into tubes as conduits for peripheral nerve regeneration. J. Biomed. Mater. Res., 63(5):591-600, 2002.

Mohammad, J.; Shenaq, J.; Rabinovsky, E. \& Shenaq, S. Modulation of peripheral nerve regeneration: a tissueengineering approach. The role of amnion tube nerve conduit across a 1-centimeter nerve gap. Plast. Reconstr. Surg., 105(2):660-6, 2001.

Sondell, M.; Lundborg, G. \& Kanje, M. Regeneration of the rat sciatic nerve into allografts made acellular through chemieal extraction. Brain Res., 795(1-2):44-54, 1998.

Sun, M. X.; Tang, J. S. \& Xu, W. J. Experimental study on chemical extracted acellular nerve allograf. Chin. J. Orthop., 26(3):26771, 2006.

Tang, F.; Shang, K.; Wang, X. \& Gu, J. Differentiation of embryonic stem cell to as trocytes visualized by green fluorescent protein. Cell. Mol. Neurobiol., 22(1):95-100, 2002.

Toba, T.; Nakamura, T.; Shimizu, Y.; Matsumoto, K.; Ohnishi, K.; Fukuda, S.; et al. Regeneration of canine peroneal nerve with the use of a polyglycolic acid-collagen tube filled with lamininsoaked collagen sponge: a comparative study of collagen sponge and collagen fibers as filling materials for nerve conduits. J. Biomed. Mater. Res., 58(6):622-30, 2006.

Xu, J.; Varitimidis, S. E.; Fisher, K. J.; Tomaino, M. M. \& Sotereanos, D. G. The effect of wrapping scarred nerves with autogenous vein graft to treat recurrent chronic nerve compression. J. Hand Surg. Am., 25(1):93-103, 2007.

Zhong, H.; Chen, B.; Lu, S.; Zhao, M.; Guo, Y. \& Hou, S. Motor functional recovery after sciatic nerve gap repair by acellular nerve allograft through chemical extraction in canines. Chin. J. Traumatol., 18:533-5, 2002.

Correspondence to:

Yan-Ru-Zhang

Department of Orthopaedics

The First Affiliated Hospital

ZhengZhou University

Zhengzhou, 450052

CHINA

Email: zhangyanru818@aliyun.com

Received: 22-01-2013

Accepted: 01-06-2013 